\title{
Gene $\times$ Environment Effects: Stress and Memory Dysfunctions Caused by Stress and Gonadal Factor Irregularities during Puberty in Control and TGF- $\alpha$ Hypomorphic Mice
}

\author{
Kyoko Koshibu*,' and Pat Levitt*,2 \\ 'Department of Neurobiology and Center for Neural Basis of Cognition, University of Pittsburgh, Pittsburgh, PA, USA; ${ }^{2}$ Department of \\ Pharmacology and Vanderbilt Kennedy Center for Research on Human Development, Vanderbilt University, Nashville, TN, USA
}

\begin{abstract}
The maturation of many neural functions occurs during puberty. An abnormal development of these processes, in the context of genetic vulnerability, may result in sex- and age-dependent penetrance of neuropsychiatric disorders. Reduced transforming growth factors- $\alpha$ (TGF- $\alpha$ ) expression in Waved-I (Wa-l) mice impairs the stress response and fear memory in adult males, but are absent or far less prominent in adult females and in pubertal males. Gonadectomy around the onset of puberty, when the mutant anatomical and behavioral phenotypes are undetectable, results in significant gene $\times$ environment effects. Adult control males show reduced physiological stress response as a result of gonadectomy, but not adult Wa-I males. In females, pubertal gonadectomy elevates specific anxiety parameters only in adult control mice. There also are general sex-specific effects of pubertal gonadectomy on adult stress and fear memory. Surgical stress alone also induces sex- and genotype-dependent effects, albeit in different behavioral parameters than those affected by gonadectomy. We conclude that normal development of stress and memory processes is reliant on the levels of stress and gonadal factors during puberty, the effects of which are modulated by genetic factors and sex.

Neuropsychopharmacology (2008) 33, 557-565; doi:I 0. I038/sj.npp. I 301436; published online 2 May 2007
\end{abstract}

Keywords: TGF- $\alpha$; memory; stress; puberty; gonadal hormone; schizophrenia

\section{INTRODUCTION}

The sexual differentiation of the central nervous system (CNS) is determined by the levels of gonadal factors during development (Goy and McEwen, 1980). Although the perinatal gonadal influence is enduring (Stewart and Kolb, 1994; Kolb and Stewart, 1995; Kolb et al, 2000; Mong et al, 2001), the CNS remains malleable in response to circulating gonadal hormones throughout life, establishing further sexual dimorphism (Giedd et al, 1997). In particular, sexual differentiation of neural networks involved in stress homeostasis and memory continue to develop throughout puberty. The sex differences in the corticosterone response to stress begin to emerge late in adolescence, resulting in the highest corticosterone levels in adult female rats compared to males or prepubescent females (Ramaley, 1972; Gabriel

\footnotetext{
*Correspondence: Dr P Levitt, Department of Pharmacology, Vanderbilt Kennedy Center for Research on Human Development, Vanderbilt University, Box 40 Peabody, 230 Appleton Place, Nashville, TN 37203, USA, Tel: + I 615322 8242, Fax: + I 615322 5910, E-mail: Pat.Levitt@vanderbilt.edu or

Dr K Koshibu, Brain Research Institute, University of Zürich/ETH, Bau 55 H38, Winterthuerstrasse 190, CH-8057, Zürich, Switzerland. Tel: +4l 01635 3349, Fax: +4l 016353303 .

E-mail: koshibu@hifo.unizh.ch

Received I4 November 2006; revised 26 February 2007; accepted 27 March 2007
}

et al, 1992; Cirulli et al, 1996). Similarly, sexual dimorphism in the HPA axis response to neuroendocrine stress is detected around the onset of puberty or later in rodents (Spinedi et al, 1997). The adult-level proficiency in cognitive abilities, such as working memory and spatial ability (eg mental rotation), also is not achieved until the onset of sexual maturation or early adulthood in primates and humans (Chelune and Baer, 1986; reviewed in Woo et al, 1997; Fitch and Denenberg, 1998). In rodents, sex differences in maze learning and avoidance learning also emerge around the time of puberty, the effect of which can be altered by both neonatal and postpubertal gonadectomy (reviewed in Fitch and Denenberg, 1998).

The sexual differentiation of brain is strongly regulated by gonadal hormones, which increase dramatically during puberty in both males and females. Gonadal hormones are necessary to cope normally with adverse environmental situations. In fact, gonadectomy in adult male and female rodents can increase the behavioral stress response (Bernardi et al, 1989) and release of ACTH and corticosterone (Handa et al, 1994), which can be reversed by subcutaneous injection of testosterone or estradiol/progesterone (Gaskin and Kitay, 1971; Bernardi et al, 1989). Estrogen administration alone can increase basal corticosterone secretion and ACTH and corticosterone responses to physical and psychological stressors in both males and females (Burgess and Handa, 1992; Handa et al, 1994) and 
enhance memory performance on the radial arm maze, Tmaze, and passive avoidance conditioning (Dohanich et al, 1994; Luine and Rodriguez, 1994; Singh et al, 1994; O'Neal et al, 1996; Daniel et al, 1997; Luine et al, 1998; Sandstrom and Williams, 2001). These studies indicate that the sex differences in stress and memory processes may be partly due to the sex-dependent gonadal hormone availability in the brain even after the normal developmental milestones.

Surprisingly, although many studies have shown the effects of altered levels of gonadal hormones during adulthood, few studies have investigated the long-term effects of pubertal gonadal factor changes on adulthood behavior and resulting vulnerability to a specific genetic challenge, which in combination may lead to neuropsychiatric disorders. Our recent studies have shown that a spontaneous hypomorphic mutation(s) of transforming growth factor- $\alpha$ (TGF- $\alpha$ ) in Waved-1 (Wa-1) mice exhibit sex-dependent, post-pubertal onset of anatomical and behavioral abnormalities. TGF- $\alpha$ is a regulator of numerous early developmental processes (reviewed in Junier, 2000). Its expression is developmentally regulated, sensitive to gonadal steroids, and increases around puberty in female hypothalamus (Ma et al, 1994a,b), pituitary and adrenal glands (Koshibu et al, 2005). In Wa-1 mice, the lateral ventricles are enlarged and stress response and fear memory are compromised in adult males, but not in pubertal males or female mice (Burrows et al, 2000; Koshibu et al, 2005). Similarly, the overexpression of TGF- $\alpha$ results in sexdependent disruptions in stress behavior (Hilakivi-Clarke et al, 1992, 1993). These results suggest that an unrecognized progression of abnormal development of stress and memory neural networks during puberty may result in sexspecific penetration of mutant phenotypes.

To investigate the role of gonadal factors in establishing the stress and memory processes during puberty, in the context of genetic vulnerability, male and female mice were gonadectomized around the onset of puberty. We used the paradigm in male and female $W a-1$ mice to determine whether sex-dependent penetrance of a genetic challenge can be modulated by gonadal hormone level changes during puberty, when the mutant phenotype is not detectable. The behavior of these mice was then assessed in adulthood. The results suggest that the physical stress and modulating levels of gonadal factors during puberty have enduring long-term effects on stress and memory functions in sexand genotype-dependent manner.

\section{MATERIALS AND METHODS}

\section{Animals}

Male and female, control and $W a-1 \mathrm{C} 57 \mathrm{Bl} / 6^{\mathrm{J}}$ mice were used. The control group included both homozygous and heterozygous littermates of Wa-1 mice, because the heterozygotes did not show any abnormal phenotype in the parameters studied. Heterozygous mating pairs were purchased from Jackson Laboratory (Bar Harbor, ME) to establish the colony. All experiments utilized animals obtained through timed mating. Simple sequence repeat PCR was used to genotype the animals as described previously (Koshibu et al, 2005). Because Wa-1 has naturally wavy hair and whiskers from birth to adulthood, the genotype of $W a-1$ homozygotes was visually confirmed by this phenotype.

All mice were group-housed and maintained in a central facility at University of Pittsburgh School of Medicine in a controlled environment with a $12 \mathrm{~h}$ light/dark cycle and free access to food and water. Experiments were performed in accordance with the guidelines provided by University of Pittsburgh Institutional Animal Care and Use Committees (IACUC) and the National Institute of Health Guide for the Care and Use of Laboratory Animals. All efforts were made to minimize animal suffering and to reduce the number of animals used.

\section{Surgical Treatments}

Male and female, control and $\mathrm{Wa}-1 \mathrm{C} 57 \mathrm{Bl} / 6^{\mathrm{J}}$ mice were gonadectomized before or around the onset of puberty (P26 to 30). The secondary sexual characteristic of the onset of puberty includes descending of testis in males (Clermont and Perey, 1957) and vaginal opening in females (Crane et al, 1972; Falconer, 1984). Even in inbred mouse strains, there is individual variability in the actual age at which puberty begins. In our study, the secondary sexual traits begin to appear around or after the generally accepted times of P26 to 30. We use this period to estimate the approximate age when puberty begins in mice (Clermont and Perey, 1957; Crane et al, 1972; Falconer, 1984; Omoto et al, 2005). The gonadectomy in males and females were conducted as described in Hogan et al (1994) and Fugger et al (2000), respectively. For males, a $1-\mathrm{cm}$-transverse incision was made close to the ventral midline. The testicular fat pad and testis were exposed. The vas deferens were isolated, tied with a piece of 5-0 surgical silk suture (Henry Schein, Melville, NY), then cut to completely remove the testis. For females, two small vertical incisions were made on either sides of the spinal cord. The ovarian fat pad, ovary, and oviduct were exposed. The oviduct was isolated, tied with a 5-0 surgical silk suture, and then cut to remove the ovary. The uterine horn was placed back into the abdomen. Sham surgery involved similar incisions of the skin and peritoneal wall. The procedures were conducted using sterile instruments under aseptic conditions. For anesthetic, $0.015 \mathrm{ml}$ per gram body weight of 2.5\% Avertin (2,2,2-tribromoethanol; Aldrich Chemicals Co., Milwaukee, WI) was injected into peritoneal cavity. Mice were allowed to recover on a heating pad after surgery. Ten control and eight $W a-1$ males were gonadectomized. Ten control and seven $\mathrm{Wa}-1$ males were sham-operated. Thirteen control and nine $W a-1$ females were gonadectomized. Ten control and six $\mathrm{Wa}-1$ females were sham-operated.

\section{Behavior}

All behavioral experiments were conducted in adult mice (3-4.5 months). The protocols have been described previously in detail (Koshibu et al, 2005). Briefly, general activity and anxiety were tested by open-field activity test. Mice were placed in a TruScan Photobeam Activity System (Coulbourn Instrument, Allentown, PA) for $10 \mathrm{~min}$ and the total movement time and distance, marginal zone time, stereotypy, and number of rears were determined. The stereotypic activity included repetitive behaviors, such as 
head bobbing, grooming, and paw-licking. Light/dark choice test was used as an additional test to determine the anxiety level. The TruScan Photobeam Activity System was divided into light and dark areas and the total time spent on the dark side of the arena over $10 \mathrm{~min}$ were calculated. Stress-induced hyperthermia was conducted to determine the stressassociated physiological changes (Zethof et al, 1994). In brief, mice were held in one hand and its rectal temperature was measured for $20 \mathrm{~s}$ (T1) using a Thermalert TH-5 apparatus (PhysiTemp, Cliftton, NJ). The mouse was then returned to the home cage for $10 \mathrm{~min}$, after which, rectal temperature was measured again for $20 \mathrm{~s}$. The change in temperature (dT) was calculated to determine the stress response. As originally described, the acute stressor in this paradigm is the brief restraint and insertion of the rectal probe.

Delay fear conditioning consisted of three pairs of tone ( $30 \mathrm{~s}$ continuous, $80 \mathrm{~dB}, 2000 \mathrm{~Hz}$ ) and foot shock $(-0.2 \mathrm{~mA}$ for $2 \mathrm{~s}$, overlapping the last $2 \mathrm{~s}$ of tone) with inter-trial interval of $1 \mathrm{~min}$. Memory performance was assessed by determining the freezing response of mice during training and context and tone tests, executed approximately $24 \mathrm{~h}$ after the training. A lack of movement lasting longer than $1 \mathrm{~s}$ was considered as a freezing response (freeze time/total test time $\times 100 \%)$. The shock sensitivity also was assessed by measuring the speed of movement during foot shocks (distance moved divided by $2 \mathrm{~s}$ ). The freezing response during the $1 \mathrm{~min}$ inter-trial interval will be referred to as unconditioned response context (UR context) and the tone during the training as UR tone.

We used vaginal color and opening as reliable and accurate measures of estrous cycle (Hogan et al, 1994). We did not utilize vaginal smears, to avoid any possible acute or chronic stress caused by this mode of sampling. We note that in all postpubertal females, none of the parameters was affected by the estrous cycle (data not shown). The onset of puberty was not altered in $W a-1$ males or females as determined by the physiological changes in the secondary sex properties described in Hogan et al (1994).

\section{Corticosterone Radioimmuno Assay (RIA)}

Trunk blood samples $(\sim 200-600 \mu \mathrm{l})$ were collected in microcentrifuge tubes with $20 \mu 1000$ USP U/ml heparine sodium (American Pharmaceutical Partners, Inc., Los Angeles, CA) and placed on ice. Plasma was collected by spinning the samples at approximately $1500 \times g$ for $15 \mathrm{~min}$ at $4{ }^{\circ} \mathrm{C}$ and stored at $-80^{\circ} \mathrm{C}$. The corticosterone levels were determined using Coat-A-Count Rat Corticosterone kit (Diagnostic Products Corporation, Los Angeles, CA) accordingly to the manufacturer's protocol. For the baseline level, blood was collected after an overnight individual housing with free access to food and water. For the stressed level, blood was collected immediately after the stressinduced hyperthermia test. The animals were terminated by decapitation. All samples were collected in the morning during the light-phase of the light/dark cycle, between 0830 and $1030 \mathrm{~h}$.

\section{Statistics}

A multivariate generalized linear model (GLM) and type III Sum of Squares were conducted to assess main effects of genotype and treatment and their interactions for males and females. Where appropriate, Tukey HSD posthoc was applied. The treatment groups included non-surgical (ns), sham (s), and gonadectomized (gx) groups. For fear conditioning training responses, repeated measures GLM was used. The context and pre-tone freezing responses were assessed by using the baseline freezing response during training as a covariant to normalize for any general activity differences. For tone test, the training baseline and pre-tone responses were used as covariant. Similarly, the stressed level of corticosterone was normalized to baseline corticosterone level. Any result indicating $p<0.05$ was considered statistically significant. All data are presented as estimated marginal means \pm SEM.

\section{RESULTS}

\section{Open-Field Activity}

In males, the number of rears was decreased in sham group compared to non-surgical group $(\mathrm{F}(2,62)=10.934$, $p<0.001$ ) (Table 1). No differences between genotypes or treatment groups were detected for other parameters for males. In females, total move time $(\mathrm{F}(1,54)=12.209, p=$ $0.001)$, total move distance $(\mathrm{F}(1,54)=14.489, p<0.001)$, and rear number $(\mathrm{F}(1,54)=5.291, p=0.026)$ were elevated in $W a-1$ compared to controls (Table 1 ). The stereotypy was reduced in $W a-1$ compared to control females $(\mathrm{F}(1,54)=$ 32.317, $p<0.001)$. When the treatment groups were compared, the total move distance was reduced $(\mathrm{F}(2,54)=6.563, p=0.003$, Tukey HSD $p=0.001)$ while the marginal zone time and stereotypy were increased $(\mathrm{F}(2,54)=4.569, \quad p=0.015, \quad$ Tukey $\mathrm{HSD} \quad p=0.012$; $\mathrm{F}(2,54)=10.426, p<0.001$, Tukey HSD $p<0.001)$ in gonadectomized females compared to sham surgery females (Table 1). Neither males nor females exhibited a genotypedependent treatment effect.

\section{Light/Dark Choice Test}

The gonadectomized males spent more time in the dark side than non-surgical males, but not compared to sham operated males $(\mathrm{F}(2,52)=3.545, p=0.037$, Tukey HSD $p=0.04)$ (Table 1; Supplementary Figure 1a). In females, there was a genotype-dependent treatment effect $(\mathrm{F}(2,52)=$ 3.912, $p=0.027)$. Gonadectomized control females showed increased total dark side time compared to sham-operated control females $(419.4 \pm 20.4$ vs $334.2 \pm 22.3$, respectively) (Supplementary Figure $1 \mathrm{~b}$ ), where as $W a-1$ females were not affected by gonadectomy. This change in the behavior of gonadectomized control females resulted in a genotype difference, where gonadectomized controls spent more time in dark side than gonadectomized $W a-1$ females $(419.4 \pm 20.4$ vs $325.0 \pm 22.3)$.

\section{Stress-Induced Hyperthermia Test}

In males, there were no genotype- or treatment-dependent changes in the baseline temperature, T1 (Figure 1a). When the stress-induced temperature change, dT, levels were compared, genotype-dependent treatment effect was detected $(\mathrm{F}(2,55)=6.846, p=0.002)$ (Figure $1 \mathrm{~b})$. Sham surgery 
Table I Open Field Activity and Light/Dark Choice Test

\begin{tabular}{|c|c|c|c|c|c|c|c|}
\hline & & Move time (s) & Move distance $(\mathrm{cm})$ & MZ time (s) & Rears & Stereotypy & Dark time (s) \\
\hline \multicolumn{8}{|l|}{ Males } \\
\hline \multirow[t]{2}{*}{ Genotype } & c & $439.5 \pm 5.0$ & $2309.0 \pm 69.5$ & $299.7 \pm 9.2$ & $78.5 \pm 3.5$ & $37.4 \pm 1.1$ & $361.8 \pm 13.2$ \\
\hline & w & $449.2 \pm 6.3$ & $2399.9 \pm 86.3$ & $315.6 \pm 11.4$ & $69.9 \pm 4.4$ & $37.2 \pm 1.4$ & $325.3 \pm 14.2$ \\
\hline \multirow[t]{2}{*}{ Treatment } & ns & $454.7 \pm 5.7$ & $2479.1 \pm 78.3$ & $294.3 \pm 10.4$ & $89.8 \pm 4.0$ & $36.6 \pm 1.3$ & $318.6 \pm 15.9$ \\
\hline & s & $440.8 \pm 7.9$ & $2376.6 \pm 109.2$ & $296.4 \pm 14.4$ & $71.8 \pm 5.5 *$ & $35.9 \pm 1.8$ & $332.7 \pm 17.1$ \\
\hline \multicolumn{8}{|l|}{ Females } \\
\hline \multirow[t]{2}{*}{ Genotype } & c & $414.6 \pm 4.9$ & $2037.8 \pm 62.6$ & $340.9 \pm 10.6$ & $53.8 \pm 2.9$ & $43.4 \pm 1.1$ & $355.0 \pm 12.8$ \\
\hline & $w$ & $440.3 \pm 5.5 *$ & $2397.1 \pm 70.6 *$ & $323.8 \pm 12.0$ & $64.0 \pm 3.3 *$ & $34.2 \pm 1.2 *$ & $333.7 \pm 14.7$ \\
\hline \multirow[t]{2}{*}{ Treatment } & ns & $429.3 \pm 6.0$ & $2170.3 \pm 77.7$ & $332.8 \pm 13.2$ & $64.4 \pm 3.6$ & $38.6 \pm 1.3$ & $318.2 \pm 17.1$ \\
\hline & s & $433.0 \pm 7.1$ & $2454.8 \pm 91.5$ & $302.0 \pm 15.5$ & $61.8 \pm 4.3$ & $34.4 \pm 1.6$ & $342.6 \pm 18.2$ \\
\hline
\end{tabular}

* $p<0.05$ comparing $c$ and $w, n s$ and $s$, or $s$ and gx.

${ }^{\dagger} p<0.05$ comparing $n s$ and $g x$.

All data are indicated in mean \pm SEM.

caused elevation of $\mathrm{dT}$ in $W a-1$ males $(1.9 \pm 0.2 \mathrm{~s}, 1.2 \pm$ $0.1 \mathrm{~ns})$ but not in control males $(1.8 \pm 0.2 \mathrm{~s}, 1.8 \pm 0.1 \mathrm{~ns})$. In contrast, gonadectomy reduced $\mathrm{dT}$ response in control males $(1.5 \pm 0.2 \mathrm{gx}, 1.8 \pm 0.2 \mathrm{~s})$ but not in $W a-1$ males $(1.8 \pm 0.2 \mathrm{gx}, 1.9 \pm 0.2 \mathrm{~s})$. The non-surgical $W a-1$ males showed reduced $\mathrm{dT}$, whereas the gonadectomized $W a-1$ males showed elevated dT compared to respective controls (Figure 1b).

In females, sham operation increased the $\mathrm{T} 1$ level compared to the non-surgical group $(37.0 \pm 0.2 \mathrm{~s}, 35.8 \pm$ $0.1 \mathrm{~ns} ; \mathrm{F}(2,62)=21.824, p<0.001$, Tukey HSD $p<0.001)$ (Figure 1c). Interestingly, gonadectomy caused a significant reduction in T1 (Tukey HSD $p<0.001$ ) to the level same as the non-surgical groups $(35.8 \pm 0.1 \mathrm{gx})$. When the stress response was compared, the $\mathrm{dT}$ was greater in gonadectomized females than in sham-operated females $(1.8 \pm 0.1 \mathrm{gx}$, $0.8 \pm 0.1 \mathrm{~s} ; \mathrm{F}(2,62)=11.151, p<0.003$ ) (Figure 1d). Increased stress response in gonadectomized females are in agreement with the open field activity and light dark choice test findings, which suggests that female gonadal factors are important in stress regulation for both control and mutant females. The genotype difference was detected only for the non-surgical group, where control females showed a higher dT level than $W a-1$ females (Figure 1d).

\section{Fear Conditioning Training}

In males, $W a-1$ males responded less to the foot shocks $(\mathrm{F}(1,55)=10.501, p=0.002)$ and unconditioned context $(\mathrm{F}(1,58)=4.755, p=0.034)$ than control males, independent of the treatment groups (Table 2). Both unconditioned tone and context responses were increased in gonadectomized males compared to sham-surgery males $(\mathrm{F}(2,58)=8.204$, $p=0.001$ UR tone, $\mathrm{F}(2,58)=5.855, p=0.005$ UR context) (Table 2).

Similar to $W a-1$ males, $W a-1$ females responded less to the foot shocks $(\mathrm{F}(1,52)=10.626, p=0.002)$ and unconditioned context $(\mathrm{F}(1,51)=5.131, p=0.028)$ than control females across all treatment groups (Table 2). Gonadectomy caused an increased foot shock response $(\mathrm{F}(1,52)=7.467$, a

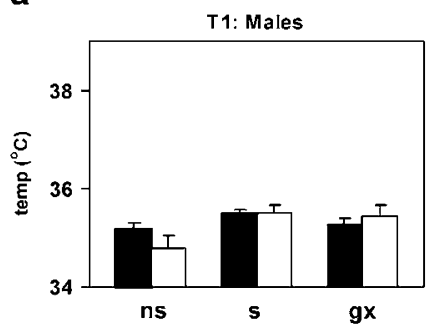

C
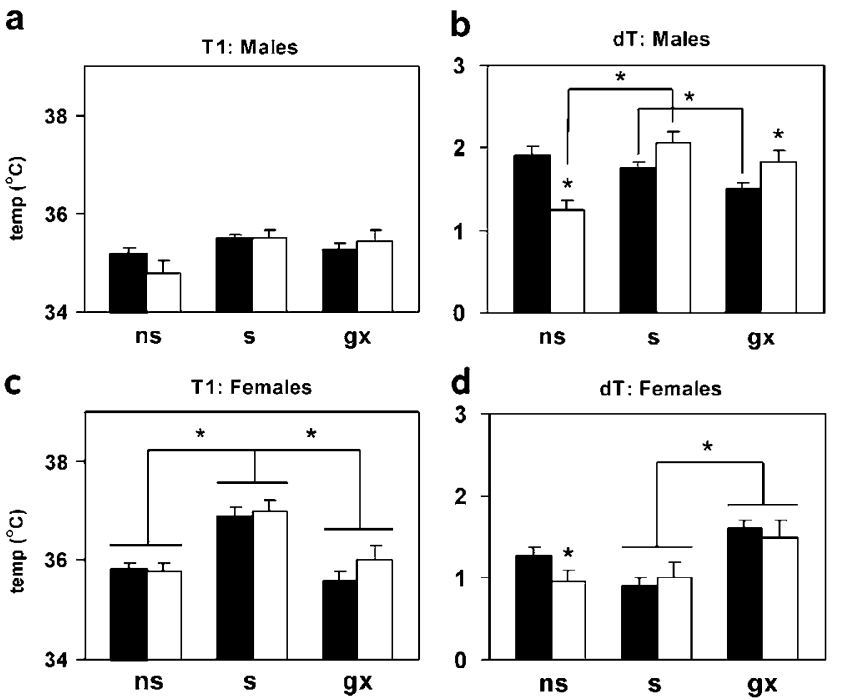

Figure I Physiological stress response. The baseline temperature $(T I)$ and stress-induced change in temperature (dT) are indicated for males ( $a$ and $b$ ) and females ( $c$ and d). The genotype and treatment specific effects are detected for dT in males. Gonadectomy reduces the dT level in control males but not in Wa-I males. The dT level is increased for both control and Wa-I gonadectomized females. Sham surgery alone eliminates the genotype differences originally observed for the non-surgical groups. Control groups are presented as black bars and Wa-I groups are presented as white bars. Statistical significant changes $(p<0.05)$ are marked with asterisks. ns = non-surgery group, $\mathrm{s}=$ sham-surgery group, $\mathrm{gx}=$ gonadectomy group.

$p=0.002)$ and unconditioned context response $(\mathrm{F}(2,51)=$ 8.242, $p=0.001)$ compared to sham-operated females.

\section{Fear Memory}

In general, $W a-1$ males exhibited reduced context memory compared to control males $(\mathrm{F}(1,58)=14.698, p<0.001)$. The adult control males showed reduced context memory as a result of surgery around the onset of puberty, but not in adult $W a-1$ males. Gonadectomy caused enhanced context 
memory compared to sham surgery, irrespective of genotype $(\mathrm{F}(2,58)=5.443, p=0.007)$ (Figure $2 \mathrm{a})$. Perhaps, as a generalized effect of the context memory, pretone response also was reduced in $W a-1$ compared to control males in general $(\mathrm{F}(1,58)=9.891, p=0.003)$ and shamsurgery resulted in a reduction in pretone response $(\mathrm{F}(2,58)=5.452, p=0.007)$ (Figure $2 \mathrm{~b})$. In contrast, shamsurgery enhanced the tone memory $(\mathrm{F}(2,54)=5.398$, $p=0.008$ ) (Figure $2 b$ ). The only genotype difference in tone memory was for the non-surgical groups where $\mathrm{Wa}-1$ males exhibited reduced tone memory compared to control males.

In females, neither context or tone memory were affected by the genotype or treatments. The only change was in the pretone response, where sham surgery caused a reduction in the pretone response compared to the non-surgical females, regardless of the genotype $(\mathrm{F}(2,58)=5.083$, $p=0.01)$.

\section{Corticosterone}

In males, both baseline and stressed levels of plasma corticosterone were elevated in the gonadectomized groups compared to the sham-surgery groups in general $(\mathrm{F}(2,42)=11.625, p<0.001$, Tukey HSD $p=0.008$ baseline, $\mathrm{F}(2,36)=144.616, p<0.001$ stressed) (Figure $3 \mathrm{a}$ ). In addition, $W a-1$ males showed a higher stressed level of corticosterone compared to control males in general $(\mathrm{F}(1,36)=13.753, p=0.001)$. In females, sham surgery elevated the stressed level of corticosterone compared to non-surgical levels $(\mathrm{F}(2,40)=9.096, p=0.001)$ (Figure 3b).

\section{DISCUSSION}

The regulation of neural functions by gonadal and stress factors are interdependent. In this study, we aimed to determine, in a genetically vulnerable state, the effect of altered levels of gonadal factors during puberty on adult stress and memory functions. Thus, the studies were designed to compare the effects of such manipulation in animals carrying a genetic mutation, which causes sexspecific, adult-onset anatomical, behavioral, and cognitive phenotypes that are reminiscent of certain human psychiatric disorders.

One of the most important findings of our studies to emphasize is that the effects of gonadectomy around the onset of puberty are genotype and sex dependent. Specifically, the alterations in gonadal factor milieu can change the regulatory functions of TGF- $\alpha$ on the maturation of stress, anxiety, and memory-related processes. For example, pubertal gonadectomy resulted in reduced stress-related responses and contextual memory in adult control males, but not in adult $W a-1$ males compared to their respective sham groups (Supplementary Table 1). In fact, the physiological stress response, measured using stress-induced hyperthermia, in $W a-1$ males was significantly elevated compared to controls as a result of pubertal gonadectomy. Interestingly, pubertal gonadectomy in females seem to affect the baseline anxiety/stress behavior in adult females more then in adult males, while the memory functions in adult females seem to remain intact but not in males (Supplementary Tables 1 and 2). This trend of greater anxiety/stress parameters being affected in females compared to males is reminiscent of our previous findings that the female $W a-1$, in particular, showed greater number of hypothalamic neurochemical changes compared to male Wa-1 (Koshibu and Levitt, 2006), suggesting that the stress homeostasis are more readily regulated by female hormones. Therefore, the study in this model system demonstrates important gene $\times$ environment interactions regarding the expression of atypical cognition and behavior after puberty. Thus, the model system we utilized here may be useful for investigating further the underlying neurobiological basis of neuropsychiatric disorders.

The integral effects of gonadal steroid hormones and altered TGF- $\alpha$ expression on stress behavior have been reported previously in TGF- $\alpha$-overexpressing transgenic mice. Gonadectomy of TGF- $\alpha$ transgenic male and female mice cause reduced immobility during Porsolt's swim test, whereas it increased the immobility duration in CD-1

Table 2 Fear Training (\% Freezing Response)

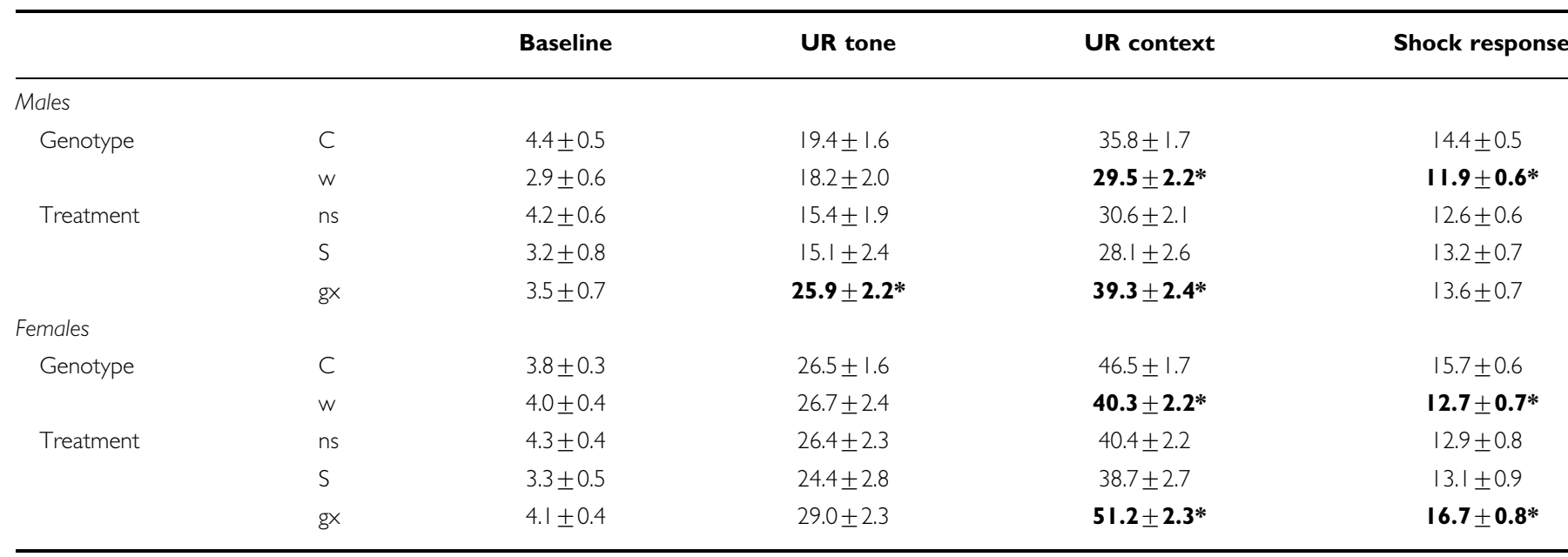

* $p<0.05$ comparing $c$ and $w$, ns and $s$, or $s$ and gx.

All data are indicated in mean \pm SEM. 

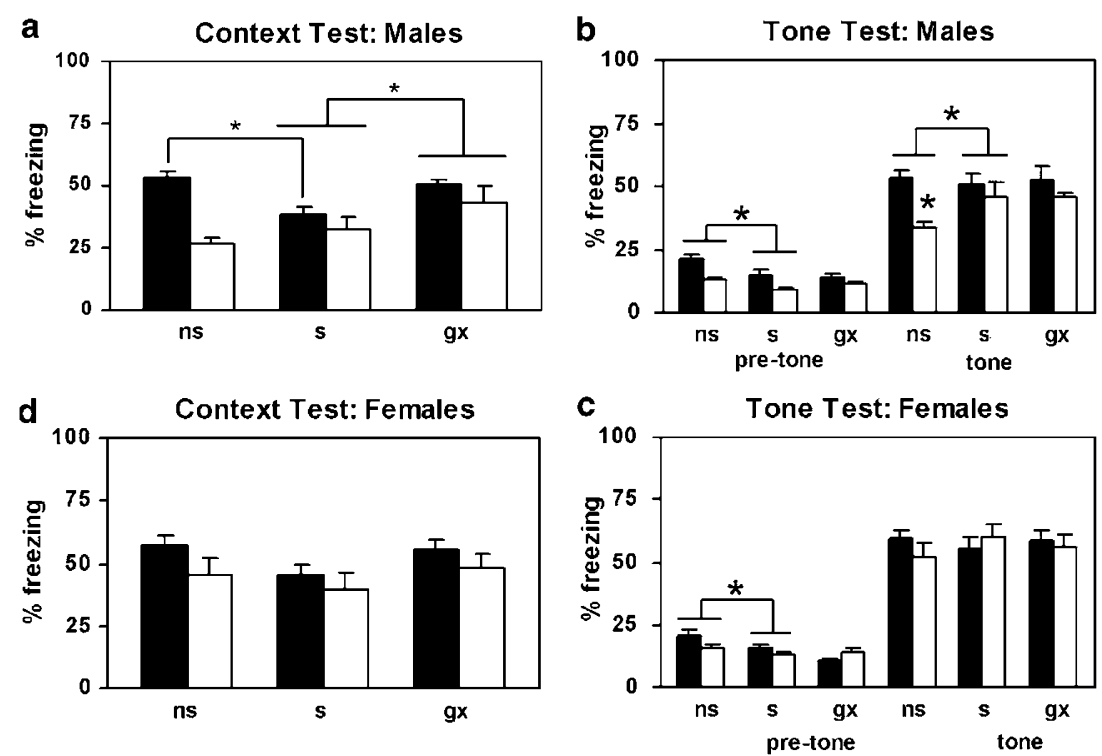

Figure 2 Context and tone fear memory. The context and tone memory performance are presented for males (a and b) and females (c and d). Gonadectomy improves memory for context in males in general. Sham surgery has sex- and genotype dependent effect on both context and tone memory. The context memory and pretone response are lower in Wa-I males compared to control males independent of the treatment (Supplementary Table I). Control groups are presented as black bars and Wa-I groups are presented as white bars. Statistical significant changes $(p<0.05)$ are marked with asterisks. ns = non-surgery group, $\mathrm{s}=$ sham-surgery group, $\mathrm{gx}=$ gonadectomy group.
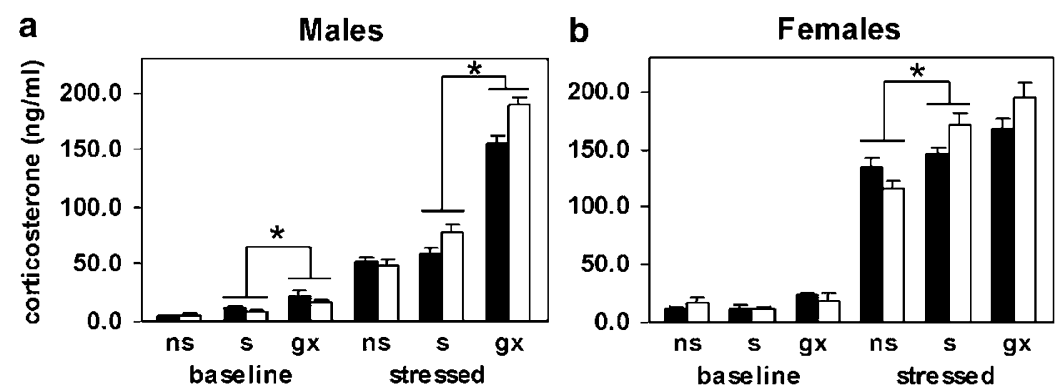

Figure 3 Baseline and stressed corticosterone levels. The corticosterone levels for males (a) and females (b) are indicated. Gonadectomy increases the baseline and stressed levels of corticosterone in males. Sham surgery elevates stressed level of corticosterone in females. No genotype differences are detected. Control groups are presented as black bars and Wa-I groups are presented as white bars. Statistical significant changes $(p<0.05)$ are marked with asterisks. $\mathrm{ns}=$ non-surgery group, $\mathrm{s}=$ sham-surgery group, $\mathrm{gx}=$ gonadectomy group.

control males (Hilakivi-Clarke, 1994). However, the genotype difference was altered only in males and not in females (Hilakivi-Clarke, 1994). In addition, there are sex-dependent tumor formation differences in TGF- $\alpha$ transgenic mice that suggest gonadal hormone involvement in TGF$\alpha$-dependent stress regulation (Takagi et al, 1992). These results are consistent with an interaction between gonadal steroid hormones and TGF- $\alpha$ in sex-specific stress regulation and memory performance.

Gonadectomy, in general, elevated specific anxiety and stress-response parameters particularly in females in our study. In females, the effect of pubertal gonadectomy on stress and anxiety are prominent in behavioral parameters but not in corticosterone levels. We hypothesize that the lack of significant change in corticosterone levels may be due to a ceiling effect of the corticosterone response. Alternatively, it is possible that other parameters of the corticosterone response might be altered, such as the time of onset or duration of the increase. A full analysis of the corticosterone response over time would be necessary to determine such changes. In contrast, in males, the behavioral anxiety effect of gonadectomy is less pronounced, whereas the corticosterone levels are significantly elevated by gonadectomy. These results indicate a possible dissociation between the corticosterone level and physiological and behavioral stress levels in sex-dependent manner. The observed elevation in stress related behavioral and biochemical changes as a result of gonadectomy are in agreement with previous reports in adult rodents (Ray and Hansen, 2004; Seale et al, 2004).

The memory performance is also affected as a result of gonadectomy in males but not in females, reflecting the sex specific effect of pubertal gonadal factors on adult memory performance. The fact that only context memory and not the tone memory was affected indicates that this effect is memory type specific. The contextual memory is reverted to the non-surgical levels in control males after gonadectomy, indicating that the male gonads may hinder stress responses but facilitate contextual memory. However, the fact that the auditory memory is not affected by sham 
surgery or gonadectomy treatment suggests that the tone memory is less sensitive to male gonadal factors. Other studies have shown that castration in adult rats can reduce inhibitory avoidance task learning and increase anxiety (Bitran et al, 1993; Vazquez-Pereyra et al, 1995; Frye, 2001; Frye and Seliga, 2001). The reasons for the discrepancies between previously reported studies and our study may be due to the timing of gonadal factor manipulation. The surgical manipulations in other studies are conducted in adulthood whereas our manipulations were performed around the onset of puberty. Thus, the effect of peripubertal gonadal manipulations may be compensated differently in adulthood.

The findings on gonadectomy in our model were confounded by the pubertal surgical stress (sham) effects, which alone induced sex- and genotype-dependent behavioral alterations in adult mice (summarized in Supplementary Tables 1 and 2). The specific mechanisms responsible for the long-term effects of stressful events experienced during adolescence are unknown. During adolescence, many systems, including glutamatergic (Huttenlocher, 1984; Insel et al, 1990), serotonergic (Dinopoulos et al, 1997), dopaminergic (Seeman et al, 1987; Lidow et al, 1991; Lidow and Rakic, 1992; Teicher et al, 1995; Tarazi et al, 1998, 1999), and GABAergic systems (Lidow and Rakic, 1992; Kellogg et al, 1993; Nurse and Lacaille, 1999), undergo synaptic pruning. Furthermore, prominent developmental anatomical transformations are evident in the prefrontal cortex and limbic brain regions of adolescents across species (reviewed in Spear, 2000). Interestingly, forebrain structures essential for cognitive functions and stress homeostasis, including prefrontal cortex, hippocampus, amygdala, and hypothalamus, possess estrogen as well as androgen receptors (reviewed in Janowsky, 2006). These receptors allow the structures to be responsive to both estrogen and testosterone. For instance, cyclical changes in dendritic spine morphology can be observed under the control of circulating estrogen levels (Woolley et al, 1996) and this can result in sex-dependent differences in spine density (Shors et al, 2001) in hippocampus. In addition, there are indications that the manipulation of gonadal hormones can result in altered levels of NE, DA, 5-HT, glutamate and GABA in prefrontal cortex and hippocampus in a gonadal hormone- and structuredependent manner (Luine et al, 1998; Bowman et al, 2004). Given these significant effects of gonadal hormones, there are likely to be many neural changes that can occur in these brain structures, in addition to the gonadal-independent developmental changes. Thus, these maturation processes of neural systems during the time of significant gonadal hormone flux in adolescence may, in part, underlie the sensitivity and permanency of the environmental influences during this period of development on adult behavior.

We also noted the novel finding that the effect of stress at puberty differs depending on genetic background, indicating that the environmental factors and genetic disposition are both crucial for the development and detection of abnormal neural functions. For some parameters, pubertal stress appears to ameliorate the mutant phenotype of the $W a-1$ genetic challenge in adulthood. For example, the sham surgery in $W a-1$ males elevated their physiological stress response compared to non-surgical $W a-1$ males, but this did not occur in control males. In addition, context memory is specifically reduced as a result of pubertal surgical stress in control males, but not in $W a-1$ males. The results are in agreement with the previous studies indicating emotional learning and memory are modulated by the stress level of animals (Maier, 1990; Shors and Servatius, 1995; Kirschbaum et al, 1996; Roozendaal and McGaugh, 1996; Sandi et al, 1997; Shors and Servatius, 1997; de Quervain et al, 1998; Buchanan and Lovallo, 2001). Moreover, differential pathophysiological effects of environmental factors can be dependent on the genetic predisposition for some human psychiatric disorders, such as depression (Kramer, 2005; Rutter, 2005; reviewed in Rutter et al, 2003, 2006a,b). We suggest that the Wa-1 mutant mouse will serve as an important model for understanding the developmental and gene $\times$ environment-interaction mechanisms that result in increased disease vulnerability in adulthood.

\section{ACKNOWLEDGEMENTS}

This work was supported in part by NSF IGERT predoctoral grant DGE-9987588 and CNBC, University of Pittsburgh (KK) and NIH MH45507, NICHD HD015052 to the Vanderbilt Kennedy Center DDRC (PL).

\section{DISCLOSURE/CONFLICT OF INTEREST}

We declare that, except for income received from our primary employer, no financial support or compensation has been received from any individual or corporate entity over the past 3 years for research or professional service and there are no personal financial holdings that could be perceived as constituting a potential conflict of interest.

\section{REFERENCES}

Bernardi M, Genedani S, Tagliavini S, Bertolini A (1989). Effect of castration and testosterone in experimental models of depression in mice. Behav Neurosci 103: 1148-1150.

Bitran D, Kellogg CK, Hilvers RJ (1993). Treatment with an anabolic-androgenic steroid affects anxiety-related behavior and alters the sensitivity of cortical GABAA receptors in the rat. Horm Behav 27: 568-583.

Bowman RE, MacLusky NJ, Sarmiento Y, Frankfurt M, Gordon M, Luine VN (2004). Sexually dimorphic effects of prenatal stress on cognition, hormonal responses, and central neurotransmitters. Endocrinology 145: 3778-3787.

Buchanan TW, Lovallo WR (2001). Enhanced memory for emotional material following stress-level cortisol treatment in humans. Psychoneuroendocrinology 26: 307-317.

Burgess LH, Handa RJ (1992). Chronic estrogen-induced alterations in adrenocorticotropin and corticosterone secretion, and glucocorticoid receptor-mediated functions in female rats. Endocrinology 131: 1261-1269.

Burrows RC, Levitt P, Shors TJ (2000). Postnatal decrease in transforming growth factor alpha is associated with enlarged ventricles, deficient amygdaloid vasculature and performance deficits. Neuroscience 96: 825-836.

Chelune GJ, Baer RA (1986). Developmental norms for the Wisconsin Card Sorting test. J Clin Exp Neuropsychol 8: 219-228.

Cirulli F, Terranova ML, Laviola G (1996). Affiliation in periadolescent rats: behavioral and corticosterone response to social reunion with familiar or unfamiliar partners. Pharmacol Biochem Behav 54: 99-105. 
Clermont Y, Perey B (1957). Quantitative study of the cell population of the seminiferous tubules in immature rats. Am J Anat 100: 241-267.

Crane DS, Warnick AC, Koger M, Rodriguez RE (1972). Relation of age and weight at puberty to reproductive performance in two lines of mice selected for 42-day weight. J Anim Sci 34: 596-600.

Daniel JM, Fader AJ, Spencer AL, Dohanich GP (1997). Estrogen enhances performance of female rats during acquisition of a radial arm maze. Horm Behav 32: 217-225.

de Quervain DJ, Roozendaal B, McGaugh JL (1998). Stress and glucocorticoids impair retrieval of long-term spatial memory. Nature 394: 787-790.

Dinopoulos A, Dori I, Parnavelas JG (1997). The serotonin innervation of the basal forebrain shows a transient phase during development. Brain Res Dev Brain Res 99: 38-52.

Dohanich GP, Fader AJ, Javorsky DJ (1994). Estrogen and estrogen-progesterone treatments counteract the effect of scopolamine on reinforced T-maze alternation in female rats. Behav Neurosci 108: 988-992.

Falconer DS (1984). Weight and age at puberty in female and male mice of strains selected for large and small body size. Genet Res 44: 47-72.

Fitch RH, Denenberg VH (1998). A role for ovarian hormones in sexual differentiation of the brain. Behav Brain Sci 21: 311-327, discussion 327-352.

Frye CA (2001). Estradiol tends to improve inhibitory avoidance performance in adrenalectomized male rats and reduces pyknotic cells in the dentate gyrus of adrenalectomized male and female rats. Brain Res 889: 358-363.

Frye CA, Seliga AM (2001). Testosterone increases analgesia, anxiolysis, and cognitive performance of male rats. Cogn Affect Behav Neurosci 1: 371-381.

Fugger HN, Foster TC, Gustafsson J, Rissman EF (2000). Novel effects of estradiol and estrogen receptor alpha and beta on cognitive function. Brain Res 883: 258-264.

Gabriel SM, Roncancio JR, Ruiz NS (1992). Growth hormone pulsatility and the endocrine milieu during sexual maturation in male and female rats. Neuroendocrinology 56: 619-625.

Gaskin JH, Kitay JI (1971). Hypothalamic and pituitary regulation of adrenocortical function in the hamster: effects of gonadectomy and gonadal hormone replacement. Endocrinology 89: 1047-1053.

Giedd JN, Castellanos FX, Rajapakse JC, Vaituzis AC, Rapoport JL (1997). Sexual dimorphism of the developing human brain. Prog Neuro-Psychopharmacol Biol Psychiatry 21: 1185-1201.

Goy WG, McEwen BS (1980). Sex Differ Brain. The MIT Press: Cambridge, MA.

Handa RJ, Nunley KM, Lorens SA, Louie JP, McGivern RF, Bollnow MR (1994). Androgen regulation of adrenocorticotropin and corticosterone secretion in the male rat following novelty and foot shock stressors. Physiol Behav 55: 117-124.

Hilakivi-Clarke L (1994). Overexpression of transforming growth factor alpha in transgenic mice alters nonreproductive, sexrelated behavioral differences: interaction with gonadal hormones. Behav Neurosci 108: 410-417.

Hilakivi-Clarke LA, Arora PK, Clarke R, Wright A, Lippman ME, Dickson RB (1993). Opposing behavioural alterations in male and female transgenic TGF alpha mice: association with tumour susceptibility. Br J Cancer 67: 1026-1030.

Hilakivi-Clarke LA, Arora PK, Sabol MB, Clarke R, Dickson RB, Lippman ME (1992). Alterations in behavior, steroid hormones and natural killer cell activity in male transgenic TGF alpha mice. Brain Res 588: 97-103.

Hogan B, Beddington R, Costantini F, Lacy E (1994). Manipulating the Mouse Embryo: A Laboratory Manual, 2nd edn.. pp 170-172 273-274. Cold Spring Harbor Laboratory Press: Cold Spring Harbor, NY.
Huttenlocher PR (1984). Synapse elimination and plasticity in developing human cerebral cortex. Am J Ment Defic 88: 488-496.

Insel TR, Miller LP, Gelhard RE (1990). The ontogeny of excitatory amino acid receptors in rat forebrain - I. N-methyl-D-aspartate and quisqualate receptors. Neuroscience 35: 31-43.

Janowsky JS (2006). Thinking with your gonads: testosterone and cognition. Trends Cogn Sci 10: 77-82.

Junier MP (2000). What role(s) for TGFalpha in the central nervous system? Prog Neurobiol 62: 443-473.

Kellogg CK, Taylor MK, Rodriguez-Zafra M, Pleger GL (1993). Altered stressor-induced changes in GABAA receptor function in the cerebral cortex of adult rats exposed in utero to diazepam. Pharmacol Biochem Behav 44: 267-273.

Kirschbaum C, Wolf OT, May M, Wippich W, Hellhammer DH (1996). Stress- and treatment-induced elevations of cortisol levels associated with impaired declarative memory in healthy adults. Life Sci 58: 1475-1483.

Kolb B, Gibb R, Gorny G (2000). Cortical plasticity and the development of behavior after early frontal cortical injury. Dev Neuropsychol 18: 423-444.

Kolb B, Stewart J (1995). Changes in the neonatal gonadal hormonal environment prevent behavioral sparing and alter cortical morphogenesis after early frontal cortex lesions in male and female rats. Behav Neurosci 109: 285-294.

Koshibu K, Ahrens ET, Levitt P (2005). Postpubertal sex differentiation of forebrain structures and functions depend on transforming growth factor-alpha. J Neurosci 25: 3870-3880.

Koshibu K, Levitt P (2006). Transforming growth factor-alpha induces sex-specific neurochemical imbalance in the stress- and memory-associated brain structures. Neuropharmacology 50: 807-813.

Kramer DA (2005). Commentary: gene-environment interplay in the context of genetics, epigenetics, and gene expression. J Am Acad Child Adolesc Psychiatry 44: 19-27.

Lidow MS, Goldman-Rakic PS, Rakic P (1991). Synchronized overproduction of neurotransmitter receptors in diverse regions of the primate cerebral cortex. Proc Natl Acad Sci USA 88: 10218-10221.

Lidow MS, Rakic P (1992). Scheduling of monoaminergic neurotransmitter receptor expression in the primate neocortex during postnatal development. Cereb Cortex 2: 401-416.

Luine V, Rodriguez M (1994). Effects of estradiol on radial arm maze performance of young and aged rats. Behav Neural Biol 62: 230-236.

Luine VN, Richards ST, Wu VY, Beck KD (1998). Estradiol enhances learning and memory in a spatial memory task and effects levels of monoaminergic neurotransmitters. Horm Behav 34: 149-162.

Ma YJ, Costa ME, Ojeda SR (1994a). Developmental expression of the genes encoding transforming growth factor alpha and its receptor in the hypothalamus of female rhesus macaques. Neuroendocrinology 60: 346-359.

Ma YJ, Dissen GA, Merlino G, Coquelin A, Ojeda SR (1994b). Overexpression of a human transforming growth factor-alpha (TGF alpha) transgene reveals a dual antagonistic role of TGF alpha in female sexual development. Endocrinology 135: 1392-1400.

Maier SF (1990). Role of fear in mediating shuttle escape learning deficit produced by inescapable shock. J Exp Psychol Anim Behav Process 16: 137-149.

Mong JA, Roberts RC, Kelly JJ, McCarthy MM (2001). Gonadal steroids reduce the density of axospinous synapses in the developing rat arcuate nucleus: an electron microscopy analysis. J Comp Neurol 432: 259-267.

Nurse S, Lacaille JC (1999). Late maturation of GABA(B) synaptic transmission in area CA1 of the rat hippocampus. Neuropharmacology 38: 1733-1742. 
O’Neal MF, Means LW, Poole MC, Hamm RJ (1996). Estrogen affects performance of ovariectomized rats in a two-choice water-escape working memory task. Psychoneuroendocrinology 21: 51-65.

Omoto Y, Lathe R, Warner M, Gustafsson JA (2005). Early onset of puberty and early ovarian failure in CYP7B1 knockout mice. Proc Natl Acad Sci USA 102: 2814-2819.

Ramaley JA (1972). Changes in daily serum corticosterone values in maturing male and female rats. Steroids 20: 185-197.

Ray J, Hansen S (2004). Temperament in the rat: sex differences and hormonal influences on harm avoidance and novelty seeking. Behav Neurosci 118: 488-497.

Roozendaal B, McGaugh JL (1996). Amygdaloid nuclei lesions differentially affect glucocorticoid-induced memory enhancement in an inhibitory avoidance task. Neurobiol Learn Mem 65: $1-8$.

Rutter M (2005). Environmentally mediated risks for psychopathology: research strategies and findings. J Am Acad Child Adolesc Psychiatry 44: 3-18.

Rutter M, Caspi A, Moffitt TE (2003). Using sex differences in psychopathology to study causal mechanisms: unifying issues and research strategies. J Child Psychol Psychiatry 44: 1092-1115.

Rutter M, Kim-Cohen J, Maughan B (2006). Continuities and discontinuities in psychopathology between childhood and adult life. J Child Psychol Psychiatry 47: 276-295.

Rutter M, Moffitt TE, Caspi A (2006). Gene-environment interplay and psychopathology: multiple varieties but real effects. J Child Psychol Psychiatry 47: 226-261.

Sandi C, Loscertales M, Guaza C (1997). Experience-dependent facilitating effect of corticosterone on spatial memory formation in the water maze. Eur J Neurosci 9: 637-642.

Sandstrom NJ, Williams CL (2001). Memory retention is modulated by acute estradiol and progesterone replacement. Behav Neurosci 115: 384-393.

Seale JV, Wood SA, Atkinson HC, Harbuz MS, Lightman SL (2004). Gonadal steroid replacement reverses gonadectomy-induced changes in the corticosterone pulse profile and stress-induced hypothalamic-pituitary-adrenal axis activity of male and female rats. J Neuroendocrinol 16: 989-998.

Seeman P, Bzowej NH, Guan HC, Bergeron C, Becker LE, Reynolds GP et al (1987). Human brain dopamine receptors in children and aging adults. Synapse 1: 399-404.

Shors TJ, Chua C, Falduto J (2001). Sex differences and opposite effects of stress on dendritic spine density in the male versus female hippocampus. J Neurosci 21: 6292-6297.

Shors TJ, Servatius RJ (1995). Stress-induced sensitization and facilitated learning require NMDA receptor activation. Neuroreport 6: $677-680$.
Shors TJ, Servatius RJ (1997). The contribution of stressor intensity, duration, and context to the stress-induced facilitation of associative learning. Neurobiol Learn Mem 68: 92-96.

Singh M, Meyer EM, Millard WJ, Simpkins JW (1994). Ovarian steroid deprivation results in a reversible learning impairment and compromised cholinergic function in female SpragueDawley rats. Brain Res 644: 305-312.

Spear LP (2000). The adolescent brain and age-related behavioral manifestations. Neurosci Biobehav Rev 24: 417-463.

Spinedi E, Chisari A, Pralong F, Gaillard RC (1997). Sexual dimorphism in the mouse hypothalamic-pituitary-adrenal axis function after endotoxin and insulin stresses during development. Neuroimmunomodulation 4: 77-83.

Stewart J, Kolb B (1994). Dendritic branching in cortical pyramidal cells in response to ovariectomy in adult female rats: suppression by neonatal exposure to testosterone. Brain Res 654: 149-154.

Takagi H, Sharp R, Hammermeister C, Goodrow T, Bradley MO, Fausto $\mathrm{N}$ et al (1992). Molecular and genetic analysis of liver oncogenesis in transforming growth factor alpha transgenic mice. Cancer Res 52: 5171-5177.

Tarazi FI, Tomasini EC, Baldessarini RJ (1998). Postnatal development of dopamine D4-like receptors in rat forebrain regions: comparison with D2-like receptors. Brain Res Dev Brain Res 110: 227-233.

Tarazi FI, Tomasini EC, Baldessarini RJ (1999). Postnatal development of dopamine D1-like receptors in rat cortical and striatolimbic brain regions: an autoradiographic study. Dev Neurosci 21: 43-49.

Teicher MH, Andersen SL, Hostetter Jr JC (1995). Evidence for dopamine receptor pruning between adolescence and adulthood in striatum but not nucleus accumbens. Brain Res Dev Brain Res 89: $167-172$.

Vazquez-Pereyra F, Rivas-Arancibia S, Loaeza-Del Castillo A, Schneider-Rivas S (1995). Modulation of short term and long term memory by steroid sexual hormones. Life Sci 56: PL255-260.

Woo TU, Pucak ML, Kye CH, Matus CV, Lewis DA (1997). Peripubertal refinement of the intrinsic and associational circuitry in monkey prefrontal cortex. Neuroscience 80: $1149-1158$.

Woolley CS, Wenzel HJ, Schwartzkroin PA (1996). Estradiol increases the frequency of multiple synapse boutons in the hippocampal CA1 region of the adult female rat. J Comp Neurol 373: 108-117.

Zethof TJ, Van der Heyden JA, Tolboom JT, Olivier B (1994). Stress-induced hyperthermia in mice: a methodological study. Physiol Behav 55: 109-115.

Supplementary Information accompanies the paper on the Neuropsychopharmacology website (http://www.nature.com/npp) 